\title{
POPULISMO Y NEOPOPULISMO EN LA REVOLUCIÓN BOLIVARIANA
}

\section{Populism and neopopulism in the Bolivarian Revolution}

\author{
José Gregorio Petit Primera*
}

\section{RESUMEN}

Este trabajo tiene como objetivo fundamental verificar si en la Revolución Bolivariana están presente elementos teóricos de lo que estudiosos de la ciencia política denominan populismo, y más recientemente neopopulismo. En ese sentido, se utilizó una metodología a través de una investigación de carácter descriptiva mediante el uso de fuentes primarias, de autores como Weyland (2003), Koeneke (2003), Conniff (2003), Vilas (2003), Arenas (2005), Laclau (2005), Ugalde y González (2007), Freidenberg (2007), Panizza (2009), Hawkins (2010), Sánchez (2010) y De la Torre (2010). Los hallazgos demuestran existencia de rasgos de ambas categorías políticas: predominio del personalismo político, discurso de confrontación amigo-enemigo, el carácter redistributivo, la concentración del poder estatal, la destrucción o inutilización de fuentes productivas y la anulación del mercado como principal actor en la asignación de recursos, la vuelta hacia un Estado empresario, y un predominio del discurso ideológico sobre las buenas medidas de política económica encaminadas a evadir la pobreza y solucionar las diversas inequidades sociales. Todo ello enmarcado en un modelo político del "Socialismo del Siglo XXI". Una característica clave del neopopulismo es el surgimiento de un líder outsider emergente, sin ataduras o dependencia de los partidos tradicionales, tal como fue el caso del fallecido presidente Hugo Chávez Frías.

Palabras claves: Populismo, neopopulismo, Revolución Bolivariana, Socialismo del Siglo XXI, líder outsider.

RECIBIDO: Marzo 2019

ACEPTADO: Abril 2019

\footnotetext{
* PostDoctorado en Ciencia Política. Doctor en Ciencia Política. Maestría en Economía Internacional, donde ocupó el puesto No.1 en su promoción de graduación. Economista con la mención honorífica Magna Cum Laude y Premio Máxima Calificación en 2008. Premio al mérito estudiantil por la Alcaldía de Maracaibo en 2008. Licenciado en Comunicación Social, mención Periodismo Impreso. Diplomado en Formación Docente. Adscrito al Departamento de Ciencias Económicas y Administrativas, Universidad Simón Bolívar (USB). Caracas, Venezuela. Correo electrónico: josepetit@usb.ve
}

401 


\section{ABSTRACT}

This work has as its fundamental objective to verify if in the Bolivarian Revolution there are present theoretical elements of what political science scholars call populism, and more recently neopopulism. In this sense, a methodology was used through a descriptive research through the use of primary sources, from authors such as Weyland (2003), Koeneke (2003), Conniff (2003), Vilas (2003), Arenas (2005), Laclau (2005), Ugalde and González (2007), Freidenberg (2007), Panizza (2009), Hawkins (2010), Sánchez (2010) and De la Torre (2010). The findings demonstrate the existence of features of both political categories: predominance of political personalism, friendenemy confrontation discourse, the redistributive character, the concentration of state power, the destruction or uselessness of productive sources and the cancellation of the market as the main actor in the allocation of resources, the return to an entrepreneurial state, and a predominance of ideological discourse on good economic policy measures aimed at evading poverty and solving various social inequities. All this framed in a political model of "Socialism of the XXI Century". A key feature of neopopulism is the emergence of an emerging outsider leader, without ties or dependence on traditional parties, such as the case of the late President Hugo Chávez Frías.

Keywords: Populism, neopopulism, Bolivarian Revolution, Socialism of the XXI Century, outsider leader.

\section{Introducción}

Definir populismo continúa siendo una asignatura pendiente en el estudio de la política latinoamericana, aunque éste retorna con frecuencia a las agendas de investigación. El intento de desarrollar el concepto de populismo como categoría de estudio plantea altos niveles de dificultad en su uso como herramienta heurística (Dockendorff y Kaiser, 2009). Los diferentes enfoques sobre el fenómeno provienen de diversas áreas en secuencias históricas distintas, por ello parte de la literatura plantea el populismo como un fenómeno político sin contenido doctrinario preciso, lejos de una categoría política con características claramente definidas. En ese sentido, el populismo sigue siendo un puente de abordaje útil en el estudio de la política en la región, y por esta razón algunas teorías y criterios de análisis proporcionados por la Ciencia Política desde Europa Occidental y Estados Unidos resultan difícilmente exportables para el estudio de la democracia en América Latina, mientras el populismo nos entrega pistas sobre el proceso político en países como Venezuela y otras democracias cuyos precarios niveles de institucionalización favorecen la emergencia de outsiders potencialmente 
populistas (Hawkins, 2010). El análisis del neopopulismo puede resultar aún más complejo, dada la contemporaneidad de su emergencia y la menor perspectiva históricocomparativa, "por lo que el término también ha dado pie a una utilización indiscriminada" (Sánchez, 2010). A pesar de ello, Conniff (2003) sugiere un interesante marco cronológico para situar temporal y conceptualmente algunas subcategorías de populismo y neopopulismo.

En Venezuela surge el neopopulismo a partir del ascenso al poder de Hugo Chávez. En este contexto, esta investigación propone como objetivo determinar si en la Revolución Bolivariana ${ }^{1}$ están presentes aspectos o elementos teóricos de la ciencia política sobre el populismo, y más recientemente neopopulismo. En ese sentido, la metodología utilizada fue una investigación de carácter descriptiva, mediante el uso de fuentes primarias. La pregunta central que intenta responder este trabajo es la siguiente: ¿en qué medida los atributos teóricos de las categorías políticas populismo y neopopulismo están presentes en la Revolución Bolivariana?

\section{Populismo histórico o clásico. Conceptualización y rasgos característicos}

En Latinoamérica, la vertiente clásica del populismo tiene lugar en la década de 1940. Surge como una respuesta a las nuevas demandas económicas, sociales y políticas tras las migraciones campo-ciudad. Hacia la década de 1960 el concepto había ampliado tanto hasta llegar a asociarse con ideologías, estratos sociales, políticas públicas y agrupaciones específicas. En ese sentido, Koeneke (2003) destaca lo siguiente:

\footnotetext{
${ }^{1}$ La Revolución Bolivariana fue el nombre dado por Hugo Chávez y sus partidarios, al proyecto ideológico y social que comienza en Venezuela a partir de 1999, con su elección como presidente del país. Según sus partidarios, las bases teóricas de la revolución están basadas en tres fuentes: La primera corresponde al árbol de las tres raíces conformadas por el proyecto político de Simón Rodríguez (el maestro), Simón Bolívar (el líder) y Ezequiel Zamora (el guerrero) que darían contenido a la especificidad de la revolución venezolana. El primero aporta el elemento de la liberación sudamericana contra el Imperio, el segundo, la necesidad de originalidad en los proyectos de país o región, y el tercero el igualitarismo. Esta revolución está enmarcada dentro de lo que se ha denominado el "Socialismo del Siglo XXI", modelo político y económico cuyos fundamentos doctrinarios y filosóficos están recogidos en Dieterich (2006), Guerra (2006) y Koeneke (2007).
} 
La génesis del fenómeno populista ha sido trazada al período de la entre guerra, cuando las naciones del continente iniciaron la búsqueda de un nuevo modelo económico y político que reemplazara al entonces vigente. Este consistía básicamente, en lo económico, en la dependencia o sujeción a las exportaciones de materias primas y a la importación de bienes intermedios y finales, así como en la influencia predominante de los sectores agropecuarios y exportadores en el ámbito político. Con las guerras mundiales y la Gran Depresión, ese esquema, llamado "dependencia clásica", dio paso a políticas de industrialización por sustitución de importaciones, promovidas por líderes emergentes y por organizaciones políticas nuevas, entre quienes figuraron Getulio Vargas en Brasil, Juan Domingo Perón y el Movimiento Justicialista en Argentina, Víctor Raúl Haya de la Torre y el APRA en Perú, Acción Democrática (AD) en Venezuela y el Movimiento Nacionalista Revolucionario (MNR) en Bolivia. Estos actores se caracterizaron por posturas y discursos marcadamente nacionalistas-anti-imperialistas y reivindicativos, así como el énfasis en la movilización y organización de los sectores sociales hasta entonces excluidos, con el fin de conformar coaliciones políticas capaces de garantizarles una sólida base de apoyo La retórica inflamada, maniquea y a menudo demagógica se convirtió desde entonces en el sello distintivo de los populistas latinoamericanos. (p.9).

El populismo es un concepto controvertido en muchos sentidos. Para Laclau (2005) es la mejor forma de organización política, porque da mayor lugar y representatividad a clases sociales relegadas, por consiguiente; para este autor, el populismo es de las formas republicanas la mejor posible, debido a una mayor participación de grupos sociales en la pugna por el poder y los recursos. En efecto, los politólogos durante muchos años han trabajado para darle una definición significativa y precisa a esta categoría política. Por su parte, Romero (1986) ve el populismo como un tipo de movimiento caracterizado por un conjunto de concepciones sobre la y el estilo de ejercer el liderazgo. El académico puntualiza además:

Dicho de otra manera, el concepto de populismo tiene un contenido histórico político y un aspecto ideológico. Históricamente, a partir de la década del 40, el populismo latinoamericano ha representado el intento -generalmente dirigido por la clase media- de conjugar esfuerzos de varios sectores sociales para crear un sistema político de amplia participación y una economía industrializada, capaz de satisfacer las aspiraciones tanto del trabajo como del capital (p.20). 
Dornbusch y Edwards (1992) señalan tres características en torno a una definición del populismo, a saber: la movilización política, la retórica recurrente y los símbolos destinados a inspirar al pueblo, sobre la base de una coalición heterogénea donde predomina la clase trabajadora, incluye también a la vez sectores importantes de los estratos medios y altos como dirigentes. Para estos autores el populismo implica un conjunto de políticas reformistas para promover el desarrollo sin provocar un conflicto clasista explosivo, donde los programas populistas responden normalmente a los problemas del subdesarrollo "'al expandir el activismo estatal para incorporar a los trabajadores en un proceso de industrialización acelerada, mediante medidas de mejoramiento de la distribución"' (p.218).

Específicamente, el populismo entendido como un estilo estratégico o como una forma de hacer política, según Roberts (1999) posee cinco atributos definitorios 1. Un patrón de liderazgo político personalizado² y paternalista (no necesariamente carismático); 2. Coalición de apoyo multiclasista basada en los sectores populares, sean éstos urbanos (sindicalizados o informales) o rurales; 3. Forma de movilización política vertical (es decir, de "arriba-abajo"), mediante la cual se sortean o subordinan mecanismos convencionales de mediación política; 4. Ideología ecléctica y antiestablishment; y 5. Uso sistemático y expandido de métodos redistributivos y clientelares como instrumento político para generar apoyo entre los sectores populares. Entretanto, Weyland (2003), Conniff (2003), Freidenberg (2007) y De la Torre (2010) coinciden en líneas generales esta categoría política presenta los siguientes rasgos: 1 . Líder carismático con atributos de características excepcionales. 2. Relación directa líder-electorado. 3. Dependencia de la movilización de amplios segmentos de la

\footnotetext{
${ }^{2}$ Para un estudio más detallado sobre los fundamentos teóricos del personalismo político véase: Soriano, Graciela (1996). El personalismo político hispanoamericano del siglo XIX. Caracas: Monte Ávila.
} 
población (masas). 4. Relación ambigua con la democracia: apela al voto y rechaza intermediación de instituciones representativas 5. Retórica maniquea: "apela" al "pueblo" y resalta el conflicto "friend versus foe". 6. Voto y movilización pública como medio de legitimación. 7. Prácticas clientelares y de patronazgo.

En las tradiciones marxista y de la teoría de la dependencia ha existido la inclinación a entender el populismo como un movimiento político compuesto por actores y bases multiclasistas correspondientes a la etapa de Industrialización por Sustitución de Importaciones (ISI). Desde un enfoque estructuralista, Vilas (2003) definió el populismo como una modalidad de acumulación de capital que emana de una configuración determinada de la estructura productiva de la sociedad. Para este autor, el populismo correspondería con la etapa primaria del desarrollo de la industria nacional y la priorización del consumo interno sobre la base de la consolidación del mercado nacional, en fase con la movilización y manipulación de las masas bajo la organización clientelar y la represión de las mismas, utilizando una ideología de la armonía y conciliación social, símil a la pretensión liberal, pero con la diferencia la armonía no es entre individuos sino entre clases sociales.

Paniza (2009) ve en la democracia y el populismo dos categorías compatibles, por consiguiente, el populismo no es ni la forma más elevada de democracia ni su enemigo, "sino más bien un espejo en el cual la democracia se puede contemplar a sí misma, mostrando todas sus imperfecciones, en un descubrimiento de sí misma y de lo que le falta" (p.59). En cuanto al discurso populista, este autor lo describe como un modo de identificación política disponible para cualquier actor político en un campo discursivo en el que la noción de soberanía popular y su inevitable corolario, el conflicto entre dominados y dominantes, son parte central del imaginario político.

\section{Populismo y petróleo en Venezuela: ¿Dos caras de la misma moneda?}


Rómulo Betancourt (1978) denominó a su obra literaria más relevante "Venezuela, política y petróleo"’3. La principal idea de este texto es que no es posible entender la realidad política venezolana sin el mecanismo de distribución de la renta petrolera. Es decir, política y petróleo van juntos de la mano en la historia política venezolana durante la mayor parte del siglo XX. Posteriormente, Romero (1986) señala dos factores claves para explicar el proceso evolutivo de la democracia venezolana: petróleo y populismo ${ }^{4}$. Y refiere al respecto:

(...) El petróleo nos ha dado en apariencia la posibilidad de crecer aceleradamente y atacar a la vez numerosos problemas de toda índole en lo social, económico y político, sin que para ello haya sido indispensable realizar los esfuerzos de productividad, organización, ahorro e innovación que han caracterizado el desarrollo de naciones avanzadas en otras regiones del mundo...Dicho de otra manera, la riqueza derivada del petróleo abrió una gama de alternativas para el desarrollo democrático nacional durante los pasados 25 años; de ese conjunto de posibilidades el liderazgo político y económico nacional ha escogido consistentemente una línea de acción de tipo populista que es un última instancia la que ha moldeado los perfiles más nítidamente definidos de nuestra democracia (p.18).

En el análisis de Corrales y Penfold (2012), la Revolución Bolivariana ha enfocado su economía política en el mecanismo de distribución de la renta petrolera financiado por los mayores precios del petróleo de la historia, lo cual ha permitió el crecimiento del Estado y la casi desaparición del sector privado. Al respecto, Koeneke (2016), sostiene que el discurso de Hugo Chávez durante la campaña electoral de 1998, centrado en la supuesta lucha terminal entre su "polo patriótico" y la "corruptocracia puntofijista", caló hondamente entre diversos sectores sociales desencantados con la gestión de gobiernos anteriores y, especialmente, entre los estratos más pobres de la

\footnotetext{
${ }^{3}$ Rómulo Betancourt empezó a escribir so obra Venezuela, política y petróleo en 1937 y fue publicada en 1955, durante uno de sus numerosos exilios.

${ }^{4}$ Dadas las particularidades de los programas populistas apalancados en la abundancia de recursos, como es el caso del experimento chavista, variadas han sido las etiquetas que se han sugerido para distinguirlos del resto. Entre estos motes resalta el de "Petropopulismo", para describir al régimen y política aplicados por Hugo Chávez en Venezuela, el cual se define como el uso económicamente excesivo de los ingresos petroleros para obtener apoyo político.
} 
población, quienes aspiraban a ser reivindicados con los recursos del pueblo, por eso en concordancia con sus promesas electorales, la gestión de Chávez se orientó a favorecer el uso de la renta petrolera en el gasto social. Más adelante, Koeneke argumenta:

La derrota del oficialismo en los comicios parlamentarios del 6 de diciembre de 2015, el creciente descontento popular manifestado en recurrentes protestas callejeras y detectado por las encuestas de opinión pública, así como el persistente desabastecimiento de numerosos y diversos productos han llevado al gobierno no solo a profundizar su discurso sobre una supuesta guerra económica aupada por la "oligarquía" y el "imperialismo", sino además a adoptar decisiones para, en palabras del Presidente Maduro, ir "sustituyendo al petróleo como única fuente de divisas internacionales". Las concesiones en el Arco Minero del Orinoco, según él, servirían para reducir el rentismo petrolero en Venezuela. Lo que no ha admitido de manera explícita es que se estaría transitando de ese rentismo petrolero hacia un rentismo minero (p.8).

\section{La economía política del populismo}

Dornbusch y Edwards (1992), ven en el populismo económico una actitud ante la economía que enfatiza 'el crecimiento económico y la redistribución del ingreso y minimiza los riesgos de la inflación, del déficit de las finanzas públicas, de los limitantes externos y de las reacciones de los agentes económicos ante las políticas radicales violadoras de las leyes del mercado" (p.20). Para estos investigadores, los gobernantes populistas una vez en el poder comienzan a aplicar ambiciosos programas económicos para intentar redistribuir el ingreso, generar empleo y acelerar el crecimiento. Sin embargo, aunque cada episodio populista real exhibe ciertas características peculiares, Dornbush y Edwards distinguen cinco (5) fases comunes a la gran mayoría de las experiencias populistas en América Latina:

Fase 0: (el origen): La economía ha venido transitando por un periodo de estancamiento o crecimiento lento y se han profundizado las desigualdades en la distribución del ingreso lo cual, aunado al descontento generalizado, abona el terreno para el programa populista. Fase I: En la primera fase, los gobernantes ven plenamente confirmados su pronóstico y su prescripción: se elevan la producción, los salarios reales y el empleo, y las políticas macroeconómicas tiene gran éxito. Los controles aseguran que la inflación no sea un problema, y las importaciones alivian la escasez. La disminución de los 
inventarios y la disponibilidad de importaciones (financiadas mediante la desacumulación de las reservas o la suspensión de los pagos externos) absorben la expansión de la demanda con escaso efecto en la inflación. Fase II: Se crean cuellos de botella en la economía debido en parte a una fuerte expansión de la demanda de bienes nacionales y en parte a una creciente falta de divisas. Mientras que la reducción de los inventarios fue un aspecto esencial de la primera fase, los bajos niveles de los inventarios y su reposición constituyen ahora una fuente de problemas. Se hacen necesarias las correcciones de los precios y la devaluación, el control de cambios o el proteccionismo. La inflación aumenta de manera significativa, pero los salarios se mantienen. El déficit presupuestario empeora enormemente como resultado de los subsidios generalizados a los bienes de consumo básico y las divisas. Fase III: La escasez generalizada, la aceleración extrema de la inflación y una obvia deficiencia de divisas, condujeron a la fuga de capital y la desmonetización de la economía. El déficit presupuestario se deteriora violentamente a causa de un importante descenso de la recaudación fiscal y el aumento de costos de los subsidios. El gobierno intenta estabilizar reduciendo los subsidios y efectuando una depreciación real. Los salarios reales bajan drásticamente y la política se torna inestable. Se evidencia que el gobierno se encuentra en situación desesperada. Fase IV: La estabilización ortodoxa se realiza en nuevo gobierno. Con frecuencia se aplicará un programa del FMI, y cuando todo haya terminado, el salario real habrá bajado hasta un nivel significativamente menor que el prevaleciente cuando se inició todo el episodio. Además, esa declinación será muy persistente, porque la política y la economía del experimento habrán deprimido la inversión y promovido la fuga de capital. Lo extremoso de las declinaciones de los salarios reales se debe a un hecho sencillo: el capital es móvil a través de las fronteras, pero la mano de obra no lo es. El capital puede huir de las malas políticas, pero los trabajadores están atrapados. El desmantelamiento final es acompañado a menudo por grandes cambios políticos, incluido el derrocamiento violento del gobierno. La clase media sanciona estos procesos a causa de la amenaza económica del populismo. Rosenstein-Rodan ha captado esta "legitimación" del golpe, por parte de la clase media, con una ruda expresión: "Salvador Allende murió no por ser socialista, sino porque era incompetente" (p.20-21).

Una vez detalladas estas fases de travesía de una economía populista, los profesores Dornbusch y Edwards hacen una aclaratoria sobre el propósito de la descripción de este paradigma, la cual no consiste en una afirmación moralista de la economía conservadora, sino una advertencia sobre el fracaso de las políticas populistas 
en última instancia, y esta frustración en el mal desempeño de la economía, tiene siempre un costo terrible para los mismos grupos sociales más vulnerables. Esta tesis de tan destacados economistas es compartida también por Toro Hardy (2008):

Aunque el presidente Chávez pretende convencer al pueblo de que él es una especie de Bolívar redivivo, que viene a resolver los problemas de la pobrezamediante una ideología a la que él califica como "Socialismo del Siglo XXI", la realidad es que la historia evidencia que en Latinoamérica, uno tras otro, muchos países han caído en manos de políticos que recurrieron a la demagogia, confiando en la aplicación de políticas fiscales expansivas, políticas de endeudamiento y utilización de financiamientos monetarios a través de sus respectivos Bancos Centrales con el objetivo de cubrir el déficit fiscal que inexorablemente terminaba por explotar. Recurrieron a controles de cambios, se olvidaron de la disciplina fiscal e implementaron políticas distributivas disparatadas, a espaldas de las realidades de la economía (...) Si uno revisa la historia económica latinoamericana, encontrará como se repiten de manera sorprendentemente parecida, estallidos de populismo en Argentina, Brasil, Chile, México, Perú, Nicaragua y ahora en Venezuela (...) En algunas oportunidades esos gobiernos lograron propiciar períodos de expansión económica. En todos se aplicaron políticas de movilización popular, con frecuencias solapadas con programas de carácter socialista, que hicieron énfasis en la distribución indiscriminada de los ingresos, sin tomar en consideración los riesgos inflacionarios a que inexorablemente conduciría el déficit fiscal. Trágicamente, fueron los sectores más humildes-aquellos que en principio se pretendía favorecer-los que terminaron pagando el precio más alto (p.181).

En el siglo XXI algunos sistemas políticos y económicos en América Latina fueron clasificados como regímenes neopopulistas, en contraposición al populismo clásico del siglo XX. De acuerdo con la tesis de Koeneke (2003), el neopopulismo requiere de un incremento constante del gasto público, a fin de mantener el respaldo político y apoyo por parte de los sectores populares. Esta idea del académico es complementada por Ugalde y González (2007):

En el neopopulismo, el pueblo contribuye con su apoyo político al caudillo, y esto le hace acreedor del apoyo económico sustancial del mismo caudillo una vez en el gobierno. El pueblo del neopopulismo no es primero productor sino receptor de bienes y servicios (...) No habiendo en el neopopulismo idea productiva con algún viso de viabilidad, su programa económico resulta fundamentalmente distributivo, confundiéndose así con su programa social, y 
puesto que las distribuciones tienen por objeto afianzar vínculos clientelares, también con su programa político (p.10).

Si bien el trabajo de Dornbusch y Edwards (1992), demuestran de manera contundente, a través de la evidencia empírica el fracaso económico de los sistemas políticos populistas tradicionales del siglo XX, el "nuevo populismo" o "neopopulismo" no es la excepción a esta regla. Al respecto, Arévalo (2008) sugiere también la inviabilidad de este nuevo fenómeno político:

Tenemos nuevos actores económicos y políticos en América del Sur. Venezuela, Ecuador y Bolivia, tienen hoy regímenes neopopulistas. Este hecho fue posible en razón del reducido desarrollo económico, el desempleo y las malas condiciones sociales. El sistema neopopulista en América del Sur podría estar condenado al fracaso pues se sustenta en la exportación de recursos naturales y el precio de mercado de estos es volátil. De otro lado, el neopopulismo requiere para su permanencia del creciente gasto público, el cual resulta insostenible en el largo plazo (p.140).

En otro orden de ideas, la evidencia empírica sugiere un incremento del gasto público social por parte de la Revolución Bolivariana. El estudio del economista Petit (2010) demuestra indudablemente el efecto de la política fiscal expansiva promovida por los altos ingresos petroleros, la cual contribuyó al rápido crecimiento de la economía venezolana a partir de 2004, ' 'lo que ha permitido al gobierno el incremento del gasto público, y por ende del gasto social, principalmente en educación y salud" (p.30). En otra relevante investigación el sociólogo Aponte (2015) corrobora lo siguiente:

En Venezuela este tipo de gasto, canaliza más de la mitad de los recursos financieros del Estado, lo que es una nítida muestra de su relevancia. Pero además, en el marco de los períodos presidenciales de Hugo Chávez, entre 1999 y 2012, esa importancia se acentuó por la alta prioridad que el régimen político le atribuyó a lo social. A ese respecto podemos adelantar que, al menos en los años 2006-2009 y 2011-2012, se realizaron las más cuantiosas erogaciones en materia social de toda la historia de las finanzas públicas venezolanas, superando claramente los máximos niveles que había alcanzado el gasto social en 1978, 1981 y 1997, al amparo de anteriores auges de los 
ingresos petroleros. Razones como las expuestas, que ilustran la significación analítica del gasto social, lo convierten en una de las variables esenciales para la periodización de la política social durante las gestiones del presidente Chávez (p.23).

\section{Nuevo populismo del siglo XXI: rasgos característicos}

Con el gradual abandono de la estrategia de Industrialización por Sustitución de Importaciones (ISI), el fin de la guerra fría y el auge de la globalización económica habrían quedado echadas las bases para la aparición del neopopulismo en América Latina. Para Ugalde y González (2007), el origen del neopopulismo latinoamericano obedece al déficit social y político resultado de la quiebra del populismo del siglo XX y del posterior fracaso del proyecto "neoliberal". Estos hechos dieron lugar no sólo a un giro hacia la izquierda, sino también a dos modelos con contenidos sociopolíticos no sólo diferentes sino opuestos: "una socialdemocracia que apunta hacia la democracia social, y un neopopulismo caudillista que apunta hacia formas de totalitarismo personalista" (p.9). Por otra parte, Koeneke (2003), resalta la necesidad del neopopulismo de un incremento constante del gasto público, a fines de mantener el apoyo y respaldo popular, y describe 3 rasgos característicos de este fenómeno político:

1. La base social de los líderes y gobernantes neopopulistas está constituida principalmente por los miembros del sector informal de la economía, en tanto que la política económica de sus administraciones se orienta por el neoliberalismo y se aparta del intervencionismo estatal. 2. Adicionalmente, estos líderes tienden a ser outsiders partidistas, es decir, sin ataduras o dependencia de los partidos tradicionales, pero sí con estrecha dependencia de los medios de comunicación social, que les permiten acceder y movilizar a un sector heterogéneo y en gran medida desarraigado socialmente como el informal. 3. Los líderes neopopulistas, en una palabra, tienden a convertirse en celebridades mediáticas, carecen de vínculos con instituciones políticas tradicionales y logran triunfos electorales inesperados gracias a la resonancia favorable que su imagen pública provoca entre los informales que han ido poblando crecientemente las grandes ciudades latinoamericanas (p.9).

De acuerdo con Roberts (1999) los neopopulistas abandonaron el modelo de intervención del Estado en la economía (propio del populismo), abrazando el 
neoliberalismo, junto con un discurso más crítico hacia los partidos políticos, y dejaron de lado sectores de apoyo de los populistas como sindicatos e industriales, en función de la mayor informalidad y diversificación de la fuerza laboral, la decreciente importancia política de los trabajadores organizados y de la movilización masiva en la región. Por su parte, desde la óptica de Weyland (2003) los neopopulistas dependen más del apoyo individual de las personas articulado desde la esfera privada, en vez de un soporte construido a partir de manifestaciones colectivas materializadas en el espacio público.

De igual manera, al contrario del populismo de los años 40 o 50 del siglo $\mathrm{XX}$, el cual solía ser más conservador, específicamente en términos morales, el neopopulismo tiende a ser ideológicamente más radical, apegándose de manera más exacta a los ideales de izquierda o derecha, según sea el caso. En ese sentido, en entrevista de Fernández (2010) a el psicólogo y experto en epistemología de las ciencias sociales, Roberto Follari, éste define el neopopulismo moderno como una forma de gobierno concreto articulado "desde lo político con una teoría marxista. Implicando redistribución, atención a los de abajo, y protagonismo de los que están más excluidos del sistema económico capitalista puro" (p.10). El profesor Follari justifica su apreciación en los siguientes términos:

(...) Muchos pueden creer que tienen que elegir entre ser marxistas y ser populistas. En los hechos, muchos marxistas apoyan a Chávez, a Correa, incluso a Cristina Fernández de Kirchner. De modo que, en realidad, el marxismo es una teoría social, de la sociedad en su conjunto; mientras que el neopopulismo es una teoría de lo político._Si bien hay cierto desarrollo marxista de la teoría política, primero de Lenin y luego de Gramsci; sin duda que puede haber otras teorías políticas y el neopopulismo es una forma de gobierno concreto que puede ser articulado desde lo político con una postura teórica marxista. En ese sentido se explica que en Venezuela, Ecuador o Bolivia se hable del "Socialismo del siglo XXI"... En nuestros países, la democracia liberal es la forma política del neoliberalismo salvaje y del capitalismo más concentrado, de modo que le sirve de tapadera ideológica. Digamos que así llaman democracia al gobierno de los ricos, de las 
multinacionales, al gobierno de los poderes fácticos, que ha llevado a desastres a los sistemas políticos y de esas catástrofes han surgido los gobiernos neopopulistas. Todos estos gobiernos han surgido de la crisis total del sistema político: como fue el "Caracazo" en Venezuela, como fue "el 2001" en Argentina, la "Guerra del Agua" en Bolivia, la caída de Mahuad con la rebelión indígena en Ecuador. En realidad, el liberalismo ha fracasado porque ha sido la cara política de la esclavitud institucional hacia el sistema económico, las multinacionales y la concentración económica. En cambio el neopopulismo implica redistribución, atención a los de abajo, protagonismo de los que están excluidos del sistema económico capitalista puro. Sin dudas que incluye a muchos más sectores de los que incluye la llamada "democracia republicana" (p.11).

Arenas (2005), en su estudio se refiere al caso del gobierno de Hugo Chávez en concreto, y argumenta sobre una combinación de rasgos tanto del populismo histórico como de un populismo de generación reciente, fenómeno éste denominado por algunos sociólogos como "neopopulismo", cuya novedad consiste en el grado de afecto al militarismo por parte de la figura de Chávez, '’y al igual como otros movimientos de este corte, el gobierno chavista mantiene una relación ambigua con las instituciones democráticas y un acentuado inmediatismo que mina la institucionalidad y la democracia misma"' (p.38), por lo que allí pueden ubicarse las razones para explicar el deslizamiento de los populismos delegativos ${ }^{5}$ hacia formas autoritarias propensas a reproducir esquemas totalitarios de gobierno. Para Arenas un denominador común entre los rasgos de coincidencia entre los estudiosos del neopopulismo es el carácter de outsider de los líderes emergentes, en ese orden de ideas la socióloga destaca:

El teniente coronel cumple meridianamente este requisito. Chávez se hizo del poder sin haber hecho carrera política alguna, tal como lo sostiene una de sus compañeras del bachillerato: 'Es algo muy difícil de asimilar. Hay que ver lo que significa no haber sido concejal, no haber sido diputado, no haber sido dirigente, no haber sido un carajo en la política... y terminar de pronto siendo Presidente"' (p.43).

5 Sobre este punto véase: O’Donnell, G. (2010). Revisando la democracia delegativa. Extraído de: http://www.uam.mx/difusion/casadeltiempo/31_iv_may_2010/casa_del_tiempo_eIV_num31_02_08.pdf. $23 / 04 / 2019$. 
Motivado a su indefinición conceptual, -según Sánchez (2010)- el populismo tuvo serias complicaciones de precisión conceptual en los años noventa, debido al interés por explicar la emergencia de "outsiders" políticos, protagonistas ejecutores de las reformas estructurales del Consenso de Washington, lo cual propició la construcción de una tipología denominada "neopopulismo", para intentar sustentar la erosión de los tradicionales sistemas políticos de partidos y la descomposición de identidades nacionales como consecuencia de la pobreza y la desigualdad. En ese orden de ideas, para Vilas (2003) las concepciones sesgadas o reduccionistas del populismo (en algunos autores) abonaron el camino para la formulación de la hipótesis neopopulista.

A juicio de Roberts (1999), el error de esta configuración no está en la identificación de algunos rasgos del populismo en estas nuevas corrientes políticas emergentes, sino más bien "el neoliberalismo y el neopopulismo contienen simetrías y afinidades inesperadas", por tanto; la imprecisión la podemos identificar en dos variables: la primera orientada en la concepción de un nuevo populismo de rasgos no existentes en los gobiernos de outsiders neoliberales, como la construcción integral de actor colectivo y las políticas redistribuitivas duraderas. La segunda variable, es la generalizada por el surgimiento de los líderes de centroizquierda del siglo XXI como Lula, Chávez, Morales, Correa, entre otros, como gobiernos neopopulistas, olvidando como principal propósito la reivindicación de lo nacional- popular, la reorganización de los movimientos sociales y la definición de políticas redistributivas a nivel económico, social y cultural, elementos éstos totalmente inadaptables al contexto neoliberal, en el cual surgió el neopopulismo de los noventa.

De acuerdo con Ugalde y González (2007) al neopopulismo lo separa del populismo latinoamericano anterior en no parecer pretender una conciliación de sectores sociales con vistas a la modernización, sino más bien ha heredado del marxismo tradicional un lenguaje de confrontación social. Sin embargo, esta 
confrontación neopopulista no es de clases en el sentido marxista, y sigue por consiguiente aproximadamente la línea divisoria entre los sectores modernos y los no modernos de las sociedades latinoamericanas. Estos autores complementan esta idea de la siguiente manera:

(...) Para justificar nuestra hipótesis, comenzamos notando la mayor de las diferencias entre neopopulismo y marxismo: mientras el marxismo es, antes que nada, una Economía Política basada en una teoría de la producción industrial moderna, el neopopulismo carece absolutamente de propuesta productiva viable. Varios elementos concurren en ello. Uno primero, el ya mencionado: si las desgracias que padecemos son producidas por otros, y el caudillo tiene la solución, consistente en liberarnos de los opresores, se desarrolla muy poco la lógica productiva del presente hacia el futuro, que lleva implícita la idea de que el futuro será nuestra creación como el presente lo ha sido. En el neopopulismo, el pueblo contribuye con su apoyo político al caudillo, y esto le hace acreedor del apoyo económico sustancial del mismo caudillo una vez en el gobierno. El pueblo del neopopulismo no es primero productor sino receptor de bienes y servicios (...) No habiendo en el neopopulismo idea productiva con algún viso de viabilidad, su programa económico resulta fundamentalmente distributivo, confundiéndose así con su programa social, y puesto que las distribuciones tienen por objeto afianzar vínculos clientelares, también con su programa político. Ahora bien, para distribuir algo primero hay que tenerlo: ¿de dónde sale ello?. La respuesta en Venezuela, y el proyecto de respuesta en Bolivia y Ecuador, los únicos países que hasta ahora han proclamado su voluntad de desarrollar una revolución neopopulista, es simple: sale del subsuelo, en forma de hidrocarburos y minerales (p.10).

Desde su enfoque estructuralista, Vilas (2003), sostiene que en la medida el neopopulismo borra los "avances" de los populismos, es en realidad un anti-populismo. Sin aceptar la hipótesis neopopulista, Vilas diferencia populismo y el "supuesto" neopopulismo partiendo del carácter distributivo y la organización popular típica del primero y el "desmantelamiento" de los servicios estatales y la política distributiva en el segundo. Para Vilas el populismo promovió la participación y la integración de los sectores populares, mientras el autoritarismo caracteriza al neopopulismo; así como la integración y movilización populista transforman a los neopopulismos en exclusión, marginación y fragmentación; las grandes organizaciones de clase son reemplazadas 
por la individualización de lo social, el Estado industrial es reemplazado por la especulación financiera y el Estado regulador por el Estado privatizador.

Finalmente, a juicio de Edwards (2008), la irrupción de Chávez, Correa, Morales y los Kirchner en Argentina, aporta una serie de nuevos elementos a analizar, cuyas raíces muestran mayores grados de similitud con el populismo tradicional que los hasta ahora llamados neopopulismos-neoliberales, entre los cuales destacan: la relación líder y masas, el discurso maniqueo, el carácter redistributivo, la concentración del poder estatal, la destrucción de las fuentes productivas y la anulación del mercado como principal asignador de recursos, la vuelta hacia un Estado empresario (este proceso comienza con la nacionalización de los recursos naturales y el reparto de tierras), todo lo cual deriva en la cesación de pagos de deuda internacional, desequilibrios macroeconómicos importantes y altos niveles de inflación. Todos estos elementos constituyeron características comunes en todos los gobiernos populistas de la historia del siglo XX, como consecuencia; el resultado es 'bajas tasas de crecimiento generadas fundamentalmente por la falta de desarrollo de tres determinantes claves (...) la fortaleza de las instituciones, las políticas de competencia y la estabilidad macroeconómica" (p.39).

\section{Conclusiones}

La Revolución Bolivariana muestra grados de similitud con el populismo tradicional o clásico, entre los cuales destacan: la relación líder y masas, el discurso "maniqueo", el carácter redistributivo, la concentración del poder estatal, la destrucción o inutilización de fuentes productivas y la anulación del mercado como principal actor en la asignación de recursos, la vuelta hacia un Estado empresario (este proceso comienza con la nacionalización de los recursos naturales y el reparto de tierras), donde privilegia más el discurso ideológico sobre las buenas medidas de 
política económica encaminadas a evadir la pobreza y solucionar las diversas inequidades económicas y sociales.

En la Revolución Bolivariana están también presente rasgos de la categoría política "neopopulismo": Líder outsider emergente, como en el caso del fallecido presidente Hugo Chávez Frías, sin ataduras o dependencia de los partidos tradicionales, pero con una estrecha dependencia de los medios de comunicación social, lo cual le permitió acceder y movilizar a un sector social heterogéneo. En ese sentido, Chávez se convirtió en una celebridad mediática sin vínculos con instituciones políticas tradicionales, y logró triunfos electorales inesperados gracias a la resonancia favorable que su imagen pública provocó entre la población de Venezuela.

El neopopulismo bolivariano también aboga por la defensa de un Estado proveedor de soluciones económicas y sociales., lo cual trae como consecuencia a la vez la instauración de un modelo económico de corte redistributivo y clientelar, apoyado en la promoción y favorecimiento de organizaciones productivas no tradicionales, condición no característica de los denominados 'neopopulismos neoliberales". Como consecuencia de la decadencia de los partidos y dirigentes tradicionales, el neopopulismo trata de aprovechar esta oportunidad, y busca la formación de nuevas coaliciones políticas con renovados sectores de la sociedad, muchos de ellos promovidos y sostenidos desde el gobierno.

Otra característica del neopopulismo es la utilización de un discurso de confrontación amigo-enemigo, promoviéndose así una sintonía entre régimen y pueblo, entre el líder y el pueblo, lográndose además una polarización política en la población. Otros aspectos presentes son el predominio del personalismo político y del paternalismo en la modalidad de actuación política del líder, el desplazamiento de los sindicatos tradicionales como una fuerte base de apoyo político, y la promoción del sector informal de la economía como un actor clave en el proceso político chavista.

Finalmente, un punto clave es el elevado gasto público social, a través de la renta petrolera con el fin de mantener el apoyo popular al régimen. Este hecho ha generado en mecanismos altamente ineficientes de gestión gubernamental, ello ha 
traído como consecuencia a la vez altos niveles de corrupción. No obstante, el control de las instituciones y el discurso antiimperialista reivindicador de los pobres enmarcado en un modelo político denominado "Socialismo del Siglo XXI", permiten definir a la Revolución Bolivariana como una democracia delegativa de izquierda, concepto este último también definido como "neopopulismo de izquierda".

\section{Referencias bibliográficas}

Aponte, Carlos (2015). Ascenso y vulnerabilidad del gasto público social durante las gestiones presidenciales de Hugo Chávez: 1999-2012. Extraído de: https://www.researchgate.net/publication/318340322_Ascenso_y_vulnerabili dad_del_gasto_publico_social_en_Venezuela_1999-2012.Consulta: 23/04/2019.

Arenas, Nelly (2005). El gobierno de Hugo Chávez: Populismo de otrora y de ahora. Revista Nueva Sociedad. Vol. XXIII, No.200. Argentina (Pp.38-50).

Arévalo, Guillermo (2008). Economía y neopopulismo en la región andina Extraído de: http://dialnet.unirioja.es/servlet/articulo?codigo $=3293521$ 22/05/2016.

Consulta:

Corrales, Javier y Penfold, Michael. (2012). Un dragón en el trópico (primera edición). Editorial La Hoja del Norte. Venezuela.

Conniff, Michael (2003). Neopopulismo en América Latina. La década de los 90 y después. Revista de Ciencia Política, Vol. XXIII, No.1. Chile (Pp. 31-38).

De la Torre, Carlos (2010). Redentores populistas en el Neoliberalismo: nuevos y viejos populismos latinoamericanos. Revista Española de Ciencia Política, No. 4. España (Pp.171 - 196).

Dieterich, Heinz (2006). Hugo Chávez y el Socialismo del Siglo XXI (primera edición). Editorial Instituto Municipal de Publicaciones. Venezuela.

Dockendorff, Andre y Kaiser, Vanessa (2009). Populismo en América Latina. Una revisión de la literatura y la agenda. Revista Austral, No. 17, Universidad Austral. Chile (Pp.75-100).

Dornbusch, Rudiger y Edwards, Sebastián. (1992). La macroeconomía del populismo en América Latina (tercera edición). Fondo de Cultura Económica. México.

Edwards, Sebastián. (2008). La larga historia de América Latina con un bajo crecimiento económico. En: Schmidt, $\mathrm{P}$ y Soto, A. (comps.). Las frágiles democracias latinoamericanas. Ediciones El Mercurio Aguilar. Chile.

Fernández, Marcelo (2010). Entrevista a Roberto Follari: 'La democracia neopopulista es más democrática que la liberal". Extraído de: http://www.cecies.org/articulo.asp?id=295. Consulta: 23/04/2019. 
Freidenberg, Flavia. (2007). La Tentación Populista. Una Vía al Poder en América Latina (primera edición). Editorial Síntesis. España.

Guerra, José (2006). ¿Qué es el Socialismo del Siglo XXI? (primera edición). Librorum Editores. Venezuela.

Hawkins, Kirk (2010). Venezuela's Chavismo and Populism in Comparative perspective. (first edition). Cambridge University Press, USA.

Koeneke, Herbert (2003). Populismo y neopopulismo en Perú y Venezuela. Revista Veneconomía, Vol. 20, No.10.Venezuela (2-6).

Koeneke, Herbert (2007). El socialismo del Siglo XXI y la reforma constitucional: ¿Padre e hija o gatos del mismo saco? Revista Veneconomía. Vol.24, No.12. Venezuela (Pp.3-9).

Koeneke, Herbert (2016). El rentismo petrolero en la cultura política del venezolano. En: Peña, Carlos (comp.). Venezuela y su tradición rentista. Visiones, enfoques y evidencias. Ediciones del Instituto de Investigaciones de Ciencias Económicas y Sociales, IIES, FACES/UCV. Venezuela.

Laclau, Ernesto (2005). La Razón populista (primera edición). Fondo de Cultura Económica. Argentina.

O’Donnell, Guillermo (2010). Revisando la democracia delegativa. Extraído de:http://www.uam.mx/difusion/casadeltiempo/31_iv_may_2010/casa_del_ti empo_eIV_num31_02_08.pdf. Consulta: 23/04/2019.

Panizza, Francisco (2009). El populismo como espejo de la democracia. En: Panizza, Francisco (comp.). El populismo como espejo de la democracia. Fondo de Cultura Económica. Argentina.

Petit, José (2010). Crecimiento económico y desarrollo social en Venezuela (19992006). Revista Cuadernos Latinoamericanos. Vol. 21, No. 37. Venezuela (Pp.9-31).

Roberts, Kenneth (1999). El neoliberalismo y la transformación del populismo en América Latina. El caso peruano. En: Mackinnon, M.; Petrone, A (comps.). Populismo y neopopulismo en América Latina. El problema de la Cenicienta. Editorial Eudeba. Argentina.

Romero, Aníbal (1986). La miseria del populismo. Mitos y realidades de la democracia en Venezuela (primera edición). Editorial Panapo. Venezuela

Sánchez, Dayana (2010). Neopopulismo en Venezuela: ¿Mito o realidad? Revista Encrucijada Americana. Vol. 3, No. 2.Chile (Pp.62-77).

Soriano, Graciela (1993). El personalismo político hispanoamericano del siglo XIX (primera edición). Editorial Monte Ávila. Venezuela.

Toro Hardy, José (2008). Por ahora. La Constitución sirve para todo (primera edición). Editorial Panapo. Venezuela.

Ugalde, Luis y González, Raúl (2007). Neopopulismo en América Latina. ¿Una derecha y dos izquierdas? Extraído de https://dialnet.unirioja.es/servlet/articulo?codigo=2251191. Consulta: 28/04/2016. 
José Gregorio Petit Primera

Telos Vol. 21, No. 2 (2019). 401-421

Vilas, Carlos (2003). ¿Populismos reciclados o neoliberalismo a secas?. El mito del neopopulismo" latinoamericano. Revista venezolana de economía y ciencias sociales. Volumen 9, No. 3. Venezuela (Pp.13-36).

Weyland, Kurt (2003). Neopopulism and Neoliberalism in Latin America: How much affinity? Ponencia del XXIV Congreso Internacional de LASA, Dallas/Texas, USA. 